OLIVEIRA; Cláudio Ladeira de; SILVA, Larissa Tenfen. Discussão e técnicas de ensino em grupo: ferramentas de aprendizagem no ensino do direito. Revista Eletrônica Direito e Política, Programa de Pós-Graduação Stricto Sensu em Ciência Jurídica da UNIVALI, Itajaí, v.10, n.4, $3^{\circ}$ quadrimestre de 2015. Disponível em: www.univali.br/direitoepolitica - ISSN 1980-7791.

\title{
DISCUSSÃO E TECNICAS DE ENSINO EM GRUPO: FERRAMENTAS DE APRENDIZAGEM NO ENSINO DO DIREITO
}

\author{
DISCUSSION AND GROUP TEACHING TECHNIQUES: TOOLS FOR THE \\ TEACHING OF LAW
}

\section{Cláudio Ladeira de Oliveira ${ }^{1}$ \\ Larissa Tenfen Silva²}

SUMÁRIO: Introdução; 1. Discussão e ensino em grupo: ferramentas de aprendizagem; 1.1 Da discussão; 1.2 Ensino de grupo; 2. Técnicas de ensino em grupo; Considerações finais; Referências das fontes citadas.

\section{RESUMO}

O presente artigo tem por objetivo demonstrar a importância da discussão e do ensino em grupo como ferramentas de aprendizagem no curso de Direito. Para realização do trabalho, utiliza-se do método bibliográfico, com consultas em fontes secundárias. Desde já fica pontuado que a técnica de discussão é um eficaz instrumento no fomento das várias habilidades e competências necessárias aos alunos nos cursos de Direito, tal como exigido pelas Diretrizes Curriculares Nacionais dos Cursos de Direito, como também contribui para uma aula muita mais animada, participativa e instigante.

PALAVRAS-ChAVE: Didática; Discussão; Ensino do Direito.

\section{ABSTRACT}

This paper aims to demonstrate the importance of discussion and group teaching as learning tools in the Law 's course. To carry out this work we used bibliographic research as well as secondary sources. As established before, not only the discussion technique is an effective tool in the promotion of various skills and competencies necessary for students in Law schools - as required by the National Curriculum Guidelines for law courses, but it also makes for a much more lively, participatory and exciting class.

\footnotetext{
1 Doutor em Direito, professor do curso de Direito da Universidade Federal de Santa Catarina, Florianópolis, Santa Catarina, Brasil. claudioladeira@hotmail.com;

${ }^{2}$ Mestre em Direito, professora do Curso de Direito da Faculdade Complexo de Ensino Superior de Santa Catarina, Florianópolis, Santa Catarina, Brasil. larissatenfensilva@hotmail.com
} 
OLIVEIRA; Cláudio Ladeira de; SILVA, Larissa Tenfen. Discussão e técnicas de ensino em grupo: ferramentas de aprendizagem no ensino do direito. Revista Eletrônica Direito e Política, Programa de Pós-Graduação Stricto Sensu em Ciência Jurídica da UNIVALI, Itajaí, v.10, n.4, $3^{\circ}$ quadrimestre de 2015. Disponível em: www.univali.br/direitoepolitica - ISSN 1980-7791.

KEYWORDS: Discussion; Group teaching; Law teaching.

\section{INTRODUÇÃO}

Refletir sobre o ensino do Direito no Brasil é uma necessidade em virtude de uma conjuntura em que ainda predominam os antigos postulados de um ensino jurídico elitista, dogmático e acrítico. É verdade que, nos últimos anos, tal situação sofreu alterações importantes. Em especial, destacam-se as regulamentações mais específicas direcionadas à área jurídica emitidas pelo Ministério da Educação, como por exemplo, a Portaria do Ministério da Educação (MEC) no $1.886 / 94^{3}$, o Parecer do Conselho Nacional de Educação (CNE) no $67 / 03^{4}$, a Resolução CNE/CES no 09/20045 , bem como pela existência de várias pesquisas e diagnósticos realizados sobre a crise do ensino do Direito elaboradas pela academia, bem como por outras instituições ligadas a esfera jurídica, como a Ordem dos Advogados do Brasil (OAB) e Poder Judiciário, que influenciaram a modificações na área.

No âmbito acadêmico, uma das questões que vem ganhando cada vez mais espaço e interesse dos docentes consiste na análise do processo de ensino e aprendizagem e da busca por novas metodologias de ensino que se contraponham ao modelo de "ensino bancário", no qual o aluno é tido como um mero depositário dos conteúdos repassados pelos docentes, através da chamada "aula conferência".

Sendo o Direito uma área específica de produção e repasse de conhecimento, faz-se cada vez mais necessário refletir sobre as formas pelas quais os professores podem estimular os alunos a reflexão, a produção e a compreensão do Direito, bem como sobre a sua própria atuação profissional, buscando assim, meios para a melhor qualidade de ensino jurídico.

\footnotetext{
3 BRASIL. Ministério da Educação. Portaria no 1.886/94. Disponível em http://portal.mec.gov.br/sesu/arquivos/pdf/dir_dire.pdf. Acesso em 09/07/2015

${ }^{4}$ BRASIL. Conselho Nacional de Educação. Parecer no 67/2002, publicado no Diário Oficial da União de 2/6/2003. Referencial para as Diretrizes Curriculares Nacionais - DCN dos Cursos de Graduação. Disponível em http://portal.mec.gov.br/cne/arquivos/pdf/2003/pces067_03.pdf. Acesso em 09/07/2015

5 BRASIL. Ministério da Educação. Conselho Nacional da Educação. Resolução no 9, de 29 de setembro de 2004. Institui as Diretrizes Curriculares Nacionais do curso de graduação em Direito, bacharelado, e dá outras providências. Disponível em http://portal.mec.gov.br/cne/arquivos/pdf/rces09_04.pdf. Acesso em 09/07/2015
} 
OLIVEIRA; Cláudio Ladeira de; SILVA, Larissa Tenfen. Discussão e técnicas de ensino em grupo: ferramentas de aprendizagem no ensino do direito. Revista Eletrônica Direito e Política, Programa de Pós-Graduação Stricto Sensu em Ciência Jurídica da UNIVALI, Itajaí, v.10, n.4, $3^{\circ}$ quadrimestre de 2015. Disponível em: www.univali.br/direitoepolitica - ISSN 1980-7791.

É justamente por tais motivos que o docente deve buscar recursos a sua atuação na área da Pedagogia que tem como foco as relações educacionais, em específico, no seu ramo relacionado à Didática que visa instrumentalizar o processo de ensino pelos professores e de aprendizagem dos alunos.

Em termos gerais, o ensino tem o objetivo de assegurar a transmissão e 0 domínio dos conhecimentos, sendo uma de suas tarefas básicas a seleção e organização do conteúdo de ensino e dos métodos apropriados. Já a aprendizagem está mais voltada à assimilação ativa dos conhecimentos pelos alunos focando a relação cognitiva do discente com a matéria de estudo ao longo do processo de ensino. Por tais motivo é que o ensino não existe por si mesmo, mas na relação com a aprendizagem.

Nesta relação, a Didática pode mediar esta vinculação entre ensino e aprendizagem, devendo o professor ter plena consciência do modelo de ensino a adotar, bem como suas técnicas. É nesse sentido, com um viés centrado no modelo baseado na aprendizagem, que neste trabalho será analisado a discussão e o ensino em grupo como meios de contribuir para um ensino reflexivo e crítico na área do Direito.

Para tanto, num primeiro momento, serão apontadas algumas contribuições que a discussão e o ensino em grupo podem fomentar na relação de ensinoaprendizagem. Em seguida, serão descritas algumas variedades possíveis para trabalhar a discussão através do ensino em grupo, sendo o artigo realizado a partir do método bibliográfico e de fontes secundárias.

Desde já fica pontuado que a técnica de discussão, quando bem compreendida e conduzida pelos professores de ensino superior, em especial nos cursos de Direito, é um excelente recurso que não apenas serve para o desenvolvimento de várias habilidades e competências necessárias aos alunos, tanto em termos profissionais e pessoais, constituindo-se numa eficaz ferramenta de aprendizagem, mas que também contribui para uma aula muita mais animada, participativa e instigante, tanto para os alunos, como para os professores, que tem a oportunidade de aprender e lapidar as suas habilidades e sensibilidade profissional.

\section{DISCUSSÃO E ENSINO EM GRUPO: FERRAMENTAS DE APRENDIZAGEM}

\subsection{Da discussão}


OLIVEIRA; Cláudio Ladeira de; SILVA, Larissa Tenfen. Discussão e técnicas de ensino em grupo: ferramentas de aprendizagem no ensino do direito. Revista Eletrônica Direito e Política, Programa de Pós-Graduação Stricto Sensu em Ciência Jurídica da UNIVALI, Itajaí, v.10, n.4, $3^{\circ}$ quadrimestre de 2015. Disponível em: www.univali.br/direitoepolitica - ISSN 1980-7791.

A discussão é uma técnica pedagógica que tem como objetivo principal proporcionar o diálogo entre discentes, ou entre discentes e professores, a respeito de conteúdos técnicos, conhecimentos gerais e valores sociais, sendo amplamente utilizada no âmbito do ensino superior.

A partir do diálogo, a técnica propicia o desenvolvimento de vários outros objetivos pedagógicos importantes na formação do aluno tais como a possibilidade de um maior domínio, compreensão e favorecimento da reflexão acerca dos conhecimentos obtidos mediante as leituras ou exposições solicitadas pelo professor, uma vez que os discentes podem enfocar um mesmo assunto sob diferentes aspectos, comparar, confrontar, ressaltar semelhanças e diferenças entre eles, fazendo-o com certa independência do professor que observa e corrige quando necessário. ${ }^{6}$

Além disso, os discentes têm a oportunidade de melhorar a sua exposição oral, bem como de formular princípios com suas próprias palavras reconstruindo as ideias ensinadas, decompondo-as, levando em conta os conhecimentos anteriores acumulados. Interessante observar que o pensamento é estimulado não somente quando os alunos efetivamente participam falando durante as discussões, mas também quando há alunos que apenas ouvem de forma atenta aos colegas e professores.

Ademais, a discussão pode ajudar os estudantes a se tornarem conscientes de problemas apresentados em leituras e preleções. A discussão pode fazer com que um mesmo fato seja visto sob muitos aspectos, favorecendo a identificação de problemas que passariam despercebidos numa aula expositiva ou numa simples leitura.

A facilitação da aceitação de informações ou de teorias contrárias às crenças tradicionais ou ideias prévias é outro objetivo a ser concretizado. A discussão passa a ser a estratégia mais adequada para demonstrar aos estudantes quão diferentes podem ser as crenças e valores das pessoas e grupos. É necessário que o professor se disponha a conduzir a discussão com o propósito de promover

${ }^{6}$ GIL, Antônio Carlos. Metodologia do ensino superior. 3a ed. São Paulo: Atlas, 1997; GIL, Antônio Carlos. Didática do ensino superior. São Paulo: Atlas, 2006. 
OLIVEIRA; Cláudio Ladeira de; SILVA, Larissa Tenfen. Discussão e técnicas de ensino em grupo: ferramentas de aprendizagem no ensino do direito. Revista Eletrônica Direito e Política, Programa de Pós-Graduação Stricto Sensu em Ciência Jurídica da UNIVALI, Itajaí, v.10, n.4, $3^{\circ}$ quadrimestre de 2015. Disponível em: www.univali.br/direitoepolitica - ISSN 1980-7791.

a reflexão acerca do discutido, dos diferentes pontos de vista e que aproveite o momento para enfatizar o papel do julgamento na construção intelectual. ${ }^{7}$

A discussão pode ainda promover o envolvimento dos alunos realizando objetivos de cunho afetivo, bem como favorecendo o relacionamento entre professor e aluno. Sobre este último objetivo, é importante o professor não esquecer que a motivação para aprender passa também pelo apreço que o aluno sente que 0 professor tem por ele, bem como pela valorização de suas ideias e encorajamento de sua participação.

Para Nereci a discussão apresenta ainda outras finalidades como a de oportunizar a cooperação e o trabalho em grupo; a ampliação de conhecimentos e estudo de novas unidades pelo aluno, bem como a fixação e integração de aprendizagens anteriores, além do estímulo a pesquisa intelectual; ao uso da argumentação objetiva e lógica; a crítica fundamentada e construtiva e o pensamento reflexivo. ${ }^{8}$

\subsection{Ensino em grupo}

O ensino em grupo compreendido como sinônimo de trabalho em grupo e/ou dinâmica de grupo está relacionado às metodologias de caráter ativo, ou seja, com ênfase no modelo de ensino que enfatiza a aprendizagem, sendo por isso facilmente relacionada à técnica de discussão e a uma das suas formas de condução.

Como recuso pedagógico em sala de aula, a dinâmica de grupo passou a servir como estratégia da Pedagogia Contemporânea, ligada também a área da

\footnotetext{
7 Nesse sentido, com explica Joseph Lowman, discussão personalizada força os estudantes a encontrar a inconsistência entre seus valores sociais (especialmente quando aplicada a exemplos distantes, grandemente simbólicos) e seus comportamentos e interesses pessoais. Provavelmente os estudantes não vão mudar seus valores da noite para o dia, por causa de tal discussão, mas ganharão uma apreciação mais plena dos conceitos estudados e podem tornar-se menos convencidos de sua superioridade moral. Cf. LOWMAN, Joseph. Dominando as técnicas de ensino. Trad. Harue Ohara Avritscher. São Paulo: Atlas, 2004 p. 169).

8 NERICI, Imídeo G. Metodologia do ensino superior. Lisboa, Portugal: Fundo de Cultura,1973, p. 191-192. Como bem enfatiza a autora em questão existe uma diferença entre discussão e debate. A primeira se caracteriza por um trabalho de cooperação intelectual, enquanto a segunda enfatiza a competição intelectual. Numa discussão há o predomínio da atitude de pesquisa e a intenção de ser encontrada a verdade, ao passo que no debate predomina a intenção de convencer, de demonstrar a superioridade de um ponto de vista, de uma tese ou teoria e quase sempre apresenta contornos emocionais mais latentes.
} 
OLIVEIRA; Cláudio Ladeira de; SILVA, Larissa Tenfen. Discussão e técnicas de ensino em grupo: ferramentas de aprendizagem no ensino do direito. Revista Eletrônica Direito e Política, Programa de Pós-Graduação Stricto Sensu em Ciência Jurídica da UNIVALI, Itajaí, v.10, n.4, $3^{\circ}$ quadrimestre de 2015. Disponível em: www.univali.br/direitoepolitica - ISSN 1980-7791.

Psicologia Social ${ }^{9}$, que tem por objetivo desenvolver nos alunos o espírito crítico, o pensamento lógico, a solidariedade e a cooperação ${ }^{10}$, além prover o desenvolvimento individual e grupal.

Desta forma, o ensino em grupo é uma técnica de ênfase coletiva que visa ao aproveitamento das possibilidades que o indivíduo traz de interagir com o outro, colocando-se de forma paralela e complementar as técnicas de ensino individualizado que centram mais as suas atenções nas diferenças individuais dos alunos. É considerado um método ativo diante da utilização do grupo como meio de formação e como fator de progresso pedagógico, da utilização de motivações intrínsecas e pelo despertar da iniciativa dos alunos que tem 'de descobrir' aquilo que devem aprender ${ }^{11}$.

A noção de grupo está relacionada a um conjunto de pessoas que possuem um vínculo definível; a consciência de ser um grupo; que tenham propósitos em comum; que sejam mutuamente dependentes na satisfação de necessidades; que estabeleçam interações; e tenham habilidades para agir de maneira unificadora ${ }^{12}$.

Na relação ensino-aprendizagem o grupo pode ser caracterizado como:

conjunto de alunos que interagem em função de objetivos cooperativamente aceitos, onde a participação de cada um se traduz no pensar com o outro, no ouvir o outro, no aceitar possibilidades de reconhecer limitações existentes em si e no outro, no respeitar para ser respeitado, no agir e no crescer com o outro. ${ }^{13}$

As técnicas de dinâmica de grupo, tal como a discussão, oportunizam o desenvolvimento de diversas habilidades e características no indivíduo,

\footnotetext{
9 ALCANTARA, Alcides. A dinâmica de grupos e sua importância no ensino. Rio de Janeiro: Senai, 1973 , p. $15-19$

${ }^{10}$ VILARINHO, Lúcia Regina Goulart. Didática: temas selecionados. Rio de Janeiro: LTC, 1979, p. 70

${ }^{11}$ MUCCHIELLI, R. A formação de adultos. São Paulo: Martins Fontes, 1981; GODOY, Arilda Schimidt; CUNHA, Maria Alexandra Viegas Cortez da. Ensino em pequenos grupos. In: MOREIRA, Daniel A. (Org). Didática do ensino superior: técnicas e tendências. São Paulo: Pioneira , 2003, p. 173.

12 TURRA, Clódia Maria Godoy et al. Planejamento de ensino e avaliação. $11^{\mathrm{a}}$ ed. Porto Alegre: Sagra Luzzatto, 1975.

${ }^{13}$ TURRA, Clódia Maria Godoy et al. Planejamento de ensino e avaliação, p. 141
} 
OLIVEIRA; Cláudio Ladeira de; SILVA, Larissa Tenfen. Discussão e técnicas de ensino em grupo: ferramentas de aprendizagem no ensino do direito. Revista Eletrônica Direito e Política, Programa de Pós-Graduação Stricto Sensu em Ciência Jurídica da UNIVALI, Itajaí, v.10, n.4, $3^{\circ}$ quadrimestre de 2015. Disponível em: www.univali.br/direitoepolitica - ISSN 1980-7791.

apontando-se, desta forma, motivos importantes para sua adoção tanto de ordem social, psicológica e pedagógica. Assim destaca Almeida:

A Dinâmica de grupo possibilita uma maior vivência em sociedade, dando oportunidade ao surgimento de novos lideres e novas funções; Cria no jovem um despertar para o desenvolvimento das tendências, possibilitando-lhes inclusive uma profissão. A dinâmica de grupo, acima de tudo, funciona como democratização: leva os indivíduos a participar, a ter responsabilidades, a desenvolver o espírito de iniciativa. É também instrumento de socialização, dandoIhe oportunidade de convivência, e preparando-o para a vida futura.[...] Além disso, a dinâmica de grupo contribui para a formação da personalidade, elimina inibições e libera as limitações. Contribui para a formação e, sobretudo, para a expressão de idéias lógicas, objetivas e coerentes; satisfaz a necessidade afetiva, emocional de convivências com seus companheiros; dá condições de o educando ser ele próprio, sair de si mesmo e eliminar as grandes barreiras dos complexos. [...] Somente o trabalho em grupo possibilita a realização de uma atividade em comum. Faz com que os próprios alunos regulamentem suas energias para alcançar um determinado objetivo. O trabalho em grupo torna a ação educativa mais agradável; proporciona maior comunicação, enriquece a vivencia individual; desenvolve o espírito crítico e a criatividade; é mais motivado; dá ao educando oportunidades de expressão e êxito na aprendizagem, igualando o mundo em que vive ao mundo escolar. 0 professor passa a ser orientador da aprendizagem e não aquele que sabe tudo e tem opinião que deva ser acatada. ${ }^{14}$

Os grupos podem ser constituídos tanto de forma espontânea, quando os alunos de forma livre se reúnem por critérios de afinidade, proximidade física; preferência pessoal em torno de um líder, por exemplo, ou de forma dirigida, mediante determinação do professor e seus objetivos.

É importante ressaltar, para uma boa compreensão e utilização das práticas em grupo, da existência de dinâmicas internas e externas que influenciam a atuação coletiva. Na dinâmica interna do comportamento grupal há o surgimento de

${ }^{14}$ ALMEIDA, Paulo Nunes. O ensino globalizante em dinâmica de grupo. São Paulo: Saraiva, 1973 pp. $19 ; 21-22$ 
OLIVEIRA; Cláudio Ladeira de; SILVA, Larissa Tenfen. Discussão e técnicas de ensino em grupo: ferramentas de aprendizagem no ensino do direito. Revista Eletrônica Direito e Política, Programa de Pós-Graduação Stricto Sensu em Ciência Jurídica da UNIVALI, Itajaí, v.10, n.4, $3^{\circ}$ quadrimestre de 2015. Disponível em: www.univali.br/direitoepolitica - ISSN 1980-7791.

forças advindas dos indivíduos e aquelas que resultam das reações mútuas entre os próprios membros e entre estes e o grupo com um todo.

Como explica Alcântara:

Entre os membros (de um grupo), como sabemos, há diferenças individuais. Cada indivíduo traz consigo interesses de ordem geral e particular, impulsos, hábitos, sentimentos, crenças e valores bem definidos que até então aplicava a si próprio e que agora projeta nos demais integrantes do grupo. Além destas forças positivas [...] devemos levar em conta as forças negativas [...] tais como as angústias, frustrações, inibições e fobias que criam para o indivíduo, devido aos fracassos sofridos, problemas de ajustamento que transmitem ao grupo. Durante o processo de interação dentro do grupo, aparecem novas forças que, embora nasçam nos indivíduos, somente se manifestam devido à interação com os outros membros. [...]. Para o professor é importante observar como se realiza essa dinâmica interna e que tipos de ajustamento aos bloqueios surgiram no grupo, a fim de compreender o comportamento do educando. Esses ajustamentos funcionam como válvulas de escape mental para os fracassos e frustrações que sofreram, restabelecendo um no equilíbrio para alcançar seus objetivos. ${ }^{15}$

E continua o autor sobre as formas comuns de mecanismos de ajustamentos:

A agressão - manifesta-se em gestos ou palavras, e, até mesmo, em violência física, isto acontece quando a própria pessoa ou mesmo suas ideias não são aceitas; trata-se de um revide em que a pessoa pensa ou diz: 'não me interessa sua opinião'; a compensação - o indivíduo desvia suas energias para outros interesses procurando ajustar-se compensando a frustração sofrida, por exemplo, o indivíduo tem dificuldade para participar em reuniões e para compensar, ele se abstém, dedicando-se extraordinariamente às ações decididas pelo grupo; a racionalização - ao encontrar dificuldade para atingir o objetivo, o indivíduo, inconscientemente, se convence de que não era aquilo que desejava, por exemplo, um moderador, sentido-se frustrado por ter dirigido mal uma reunião, comenta que 'os debates não forma positivos

\footnotetext{
${ }^{15}$ ALCANTARA, Alcides. A dinâmica de grupos e sua importância no ensino. Rio de Janeiro: Senai, 1973, p.24-25
} 
OLIVEIRA; Cláudio Ladeira de; SILVA, Larissa Tenfen. Discussão e técnicas de ensino em grupo: ferramentas de aprendizagem no ensino do direito. Revista Eletrônica Direito e Política, Programa de Pós-Graduação Stricto Sensu em Ciência Jurídica da UNIVALI, Itajaí, v.10, n.4, $3^{\circ}$ quadrimestre de 2015. Disponível em: www.univali.br/direitoepolitica - ISSN 1980-7791.

porque não souberam discutir' e conclui que as discussões jamais conduzem o bem resultado; a projeção - o indivíduo transfere a outro o sentimento de sua própria inadequação, por exemplo, um indivíduo que não tenha coragem de discrepar abertamente, pode dizer 'Fulano não concorda com a sugestão, não é?'; a conversão - é a transformação da energia física em um sintoma ou queixa de doença durante ou após uma frustração, por exemplo, uma pessoa que haja querido dirigir bem uma reunião sem consegui-lo, poderá ficar enferma, realmente, em função dos resultados [...]. Em muitos casos, os sintomas são bastante reais. ${ }^{16}$

Desta forma, os ajustamentos não são bons ou maus sendo que a identificação desses fatores que causam bloqueios e frustrações serve para se escolher os tipos de ajustamento desejados, aplicando-os de forma inteligente para acarretar mais satisfação pessoal e maior rendimento grupal. Tais mecanismos apenas causas prejuízos quando usados com excesso.

Todavia, existem outras forças que atuam sobre o grupo e exercem pressão externa. São justamente estas que constituem a dinâmica externa do grupo que passa a sofrer tanto a influência dos sistemas de valores da comunidade em que está inserido, bem como outras forças específicas da própria natureza e condições em que o grupo atua.

Ainda sobre a dinâmica dos grupos, pode-se verificar que, na realização de tarefas grupais, existe a possibilidade de definição de papéis aos membros participantes. Um deles é o papel de coordenador que, dentre as várias funções, busca orientar e controlar a ação do grupo em relação aos objetivos traçados, planejando e dinamizando as realizações, integrando as conclusões, representando os membros do grupo junto ao professor e demais colegas entre outros. Ou ainda a função de secretário que pode ter a responsabilidade de registrar o plano de trabalho a ser desenvolvido, as ideias a serem apresentadas em relação ao assunto em pauta e as conclusões; ou ainda o papel de relator que é encarregado de ler e apresentar as conclusões do grupo ao professor e demais colegas.

Além desses papéis, outros podem ser desenvolvidos pelos demais membros do grupo, tais como o de observador, cronometrista, diplomata entre outros, tudo

${ }^{16}$ ALCANTARA, Alcides. A dinâmica de grupos e sua importância no ensino, p.24-25 
OLIVEIRA; Cláudio Ladeira de; SILVA, Larissa Tenfen. Discussão e técnicas de ensino em grupo: ferramentas de aprendizagem no ensino do direito. Revista Eletrônica Direito e Política, Programa de Pós-Graduação Stricto Sensu em Ciência Jurídica da UNIVALI, Itajaí, v.10, n.4, $3^{\circ}$ quadrimestre de 2015. Disponível em: www.univali.br/direitoepolitica - ISSN 1980-7791.

de acordo com o tipo de técnica de grupo apresentada e das reais necessidades do grupo. ${ }^{17}$

Como enfatiza Turra, é necessário que os membros de um grupo que desempenhem ou não uma função específica "estejam integrados no grupo e participem, com responsabilidade, das atividades desenvolvidas em busca da realização dos objetivos. ${ }^{18}$

As atividades grupais podem ser processadas em pelo menos três etapas gerais: planejamento, ação do grupo e avaliação. A etapa de planejamento consiste na determinação, pelos alunos, dos objetivos a atingir, as alternativas para ação, os recursos a serem utilizados e os papéis dos membros do grupo. A etapa ação do grupo são executadas as ações planejadas englobando a coleta de dados e materiais, a elaboração dos dados e o relatório de grupo. Já na última etapa, de avaliação, os alunos verificam se todos os objetivos foram alcançados e se o desempenho de cada um deles correspondeu às expectativas do grupo e às suas próprias. As conclusões obtidas servirão de base para novos planejamentos do grupo.

Não se pode esquecer que há uma variedade de técnicas de grupos e que devem ser selecionadas pelo professor de acordo com os objetivos a serem desenvolvidos pelos alunos, bem como as possibilidades e limitações das diferentes técnicas específicas e contextos. Assim, são fatores que podem servir de indicativo para escolha das técnicas, por exemplo, os objetivos pretendidos a serem desenvolvidos, tais como, intercâmbio de ideias, treinamento em tomada decisões, participação total, etc; a maturidade do grupo, sugerindo-se técnicas mais simples para grupos ainda não treinados na atividade grupal; o tamanho do grupo que pode variar no número de elementos componentes; o ambiente físico e recursos disponíveis; a capacidade do condutor da técnica etc. ${ }^{19}$

Ponto importante na busca pela eficiência do uso do ensino em grupo é a realização de avaliação. Todo trabalho deve ser avaliado, apontando-se os aspectos positivos e negativos, no que tange aos conteúdos trabalhos, quer em relação à estrutura da técnica ou em relação ao funcionamento dos grupos. Assim, as finalidades mais específicas da avaliação busca verificar a

\footnotetext{
17 TURRA, Clódia Maria Godoy et al. Planejamento de ensino e avaliação, p.142-143

18 TURRA, Clódia Maria Godoy et al. Planejamento de ensino e avaliação, p. 143.

${ }^{19}$ ALCANTARA, Alcides. A dinâmica de grupos e sua importância no ensino, p.27-28
} 
OLIVEIRA; Cláudio Ladeira de; SILVA, Larissa Tenfen. Discussão e técnicas de ensino em grupo: ferramentas de aprendizagem no ensino do direito. Revista Eletrônica Direito e Política, Programa de Pós-Graduação Stricto Sensu em Ciência Jurídica da UNIVALI, Itajaí, v.10, n.4, $3^{\circ}$ quadrimestre de 2015. Disponível em: www.univali.br/direitoepolitica - ISSN 1980-7791.

concretização dos objetivos pretendidos com o exercício grupal; o fornecimento de feedback aos alunos e professores, na busca por maior rendimento e interação para trabalhos futuros e desenvolvimento de senso crítico dos aluno e professores.

As avaliações podem ser feitas através do uso de fichas, questionários entre outros, elaborados especificamente para tais fins, levando-se em conta, por exemplo, o conteúdo da tarefa, o tipo de grupo; da técnica utilizada, dos objetivos, podendo ser respondidos pelo professor, pelos membros do grupo ou pelo coordenador do grupo. ${ }^{20}$

\section{TÉCNICAS DE ENSINO EM GRUPO}

Existem muitas técnicas específicas de ensino em grupo que podem ser utilizadas para desenvolver a discussão ${ }^{21}$. Neste esboço serão descritas somente algumas utilizadas na área do Direito e que realizam os objetivos propostos por um curso de Direito que fomente nos seus alunos, dentre outros, as habilidades, competências e valores de um ensino inclusivo, participativo e de qualidade.

Um primeiro conjunto de técnicas existente enfoca atividades com a sala toda. A discussão com a classe toda é muito utilizada nos cursos de graduação sendo vista como alternativa a aula expositiva. Ela acarreta vários benefícios, pois incentiva os alunos a falar em público expressando suas idéias, reflexões, experiências e vivências; estimula os discentes a ouvir uns aos outro; a dialogar; a argumentar e a respeitar opiniões diferentes, deixando claro que experiências coletivas são importantes.

Mas nem sempre tais discussões são bem sucedidas sendo necessário ao professor dominar bem o assunto a ser debatido, preparar previamente os estudantes e ter habilidade de coordenação de discussão. Exemplos de formas de discussão em grupo podem ser o modelo de discussão clássica e o modelo desenvolvente.

\footnotetext{
${ }^{20}$ VILARINHO, Lúcia Regina Goulart. Didática: temas selecionados. Rio de Janeiro: LTC, 1979, p. 77

21 Cf. ALCANTARA, Alcides. A dinâmica de grupos e sua importância no ensino. Rio de Janeiro: Senai, 1973.
} 
OLIVEIRA; Cláudio Ladeira de; SILVA, Larissa Tenfen. Discussão e técnicas de ensino em grupo: ferramentas de aprendizagem no ensino do direito. Revista Eletrônica Direito e Política, Programa de Pós-Graduação Stricto Sensu em Ciência Jurídica da UNIVALI, Itajaí, v.10, n.4, $3^{\circ}$ quadrimestre de 2015. Disponível em: www.univali.br/direitoepolitica - ISSN 1980-7791.

Conforme explica Antônio Carlos $\mathrm{Gil}^{22}$, na discussão clássica, o professor, primeiramente, define os objetivos da discussão e prepara os estudantes para participação. Em seguida, o professor dá início à discussão definindo suas regras, esclarecendo os objetivos e apresentando uma questão inicial. Na etapa seguinte, o professor passa a acompanhar a discussão ouvindo os estudantes, registrando sua participação e respondendo às suas solicitações. Ato contínuo, o professor encerra a discussão expressando o significado que teve para si ou ajudando na formulação de conclusões. Por fim, o professor pede aos estudantes que avaliem a discussão.

Já o modelo de discussão desenvolvente serve para solucionar problemas sendo que o professor deve quebrar o mesmo em partes fazendo com que todos os membros do grupo trabalhem com uma parte específica do problema ao mesmo tempo. Tal modelo pode ser usada para corrigir alguns problemas que surgem nas discussões tradicionais, ainda mais quando certos argumentos são mal desenvolvidos. São exemplos de possíveis etapas que aparecem como seqüência neste modelo à formulação do problema; após sugestão de hipóteses; em seguida a obtenção de dados relevantes; para por fim se ter a avaliação de soluções alternativas.

Além das técnicas de discussão com a sala toda existe um grande número de modelos de discussão realizada em pequenos grupos usados principalmente quando as classes apresentarem um número grande de alunos.

Um primeiro exemplo desta modalidade é o "grupo do cochicho". Esta é uma técnica simples, geralmente utilizada no contexto de uma aula expositiva. 0 professor interrompe a aula e pede aos estudantes que dialoguem com o(s) seu(s) colega (s) mais próximo (s), no mesmo lugar em que se encontram, sem se levantar, sobre algum ponto sugerido. A formação do grupo não deve durar mais de dois ou três minutos, sendo que em seguida o professor retoma a condução dos trabalhos. Tal técnica pode ser utilizada para verificar se a classe entendeu o que foi exposto, para levantar a opinião dos estudantes sobre o assunto ou mesmo para proporcionar um alívio após a apresentação de um assunto complexo ou desagradável. ${ }^{23}$

${ }^{22}$ GIL, Antônio Carlos. Metodologia do ensino superior; GIL, Antônio Carlos. Didática do ensino superior.

${ }^{23}$ GIL, Antônio Carlos. Didática do ensino superior, p. 167-168 
OLIVEIRA; Cláudio Ladeira de; SILVA, Larissa Tenfen. Discussão e técnicas de ensino em grupo: ferramentas de aprendizagem no ensino do direito. Revista Eletrônica Direito e Política, Programa de Pós-Graduação Stricto Sensu em Ciência Jurídica da UNIVALI, Itajaí, v.10, n.4, $3^{\circ}$ quadrimestre de 2015. Disponível em: www.univali.br/direitoepolitica - ISSN 1980-7791.

A Técnica do Fracionamento ou "Phillips 66" é outra forma de discussão em pequeno grupo criada por J. Donald Phillips em que seis pessoas discutem um assunto em seis minutos. É desenvolvido em quatro etapas. Na primeira o moderador, responsável pela reunião dos membros que compõe a sala, apresenta ao grande grupo a pergunta ou assunto objeto de discussão que deve ser o mesmo para todos. Em seguida, o moderador divide o grande grupo em seis grupos menores e pede que cada um deles escolha o seu coordenador e o relator, dando em seguida início aos debates. Na terceira fase, o relator de cada grupo apresenta as conclusões. Cada relator escreverá no quadro, por exemplo, as conclusões do seu grupo. Na quarta etapa, o moderador dirigirá os debates com todos os grupos para chegar a uma conclusão final.

Durante a atividade o papel dos moderados envolve as atividades de dar instruções gerais sobre o uso da técnica; estimular o interesse dos alunos pela atividade; anunciar e marcar o tempo do exercício; prestar esclarecimentos para os grupos e observar seus trabalhos; prorrogar o tempo caso seja necessário; fazer a síntese da leitura das conclusões dos relatores e a conclusão final. ${ }^{24}$

Um terceiro exemplo de trabalho em grupo é o painel integrado que pode ser realizado em três etapas distintas. Na primeira etapa a classe é dividida em grupos de quatro a seis alunos. O professor propõe para cada grupo uma tarefa a ser desenvolvida num determinado período de tempo. Após a conclusão da tarefa, cujos resultados deverão ser anotados por todos, o professor distribui entre os seus membros um número. Na segunda etapa, formam-se novos grupos com os participantes de número um de todos os grupos anteriores, pelos de número dois, três e assim sucessivamente. Estes novos grupos desenvolverão duas outras atividades, quais sejam, relatar o que ocorreu no grupo anterior e fazer nova discussão. Esta discussão ocorrerá com base em nova questão apresentada pelo professor ou com base no debater anterior. Por fim, o professor geralmente sugere um tópico mais amplo capaz de abranger as diversas discussões e conduz a discussão para um âmbito mais geral. ${ }^{25}$

\footnotetext{
24 ALCANTARA, Alcides. A dinâmica de grupos e sua importância no ensino, p. 35-36 0 objetivo da técnica é permitir e promover a participação de todos os membros do grupão (sala toda); obter as opiniões de todos os membros em um tempo muito curto; superar as inibições para falar diante dos outros; desenvolver a capacidade de síntese e concentração; agilizar o raciocínio e criar uma atitude mental de receptividade favorável à aprendizagem.
}

25 GIL, Antônio Carlos. Didática do ensino superior, p.170-171 
OLIVEIRA; Cláudio Ladeira de; SILVA, Larissa Tenfen. Discussão e técnicas de ensino em grupo: ferramentas de aprendizagem no ensino do direito. Revista Eletrônica Direito e Política, Programa de Pós-Graduação Stricto Sensu em Ciência Jurídica da UNIVALI, Itajaí, v.10, n.4, $3^{\circ}$ quadrimestre de 2015. Disponível em: www.univali.br/direitoepolitica - ISSN 1980-7791.

Uma quarta forma de discussão em pequeno grupo é a modalidade do grupo de verbalização e grupo de observação (GV/GO). Nesta técnica, metade dos alunos da classe forma um círculo central constituindo o grupo de verbalização com o objetivo de discutir certo tema ou problema, por exemplo. A outra metade da sala forma outro circulo exterior ao primeiro compondo o grupo de observação que tem a função de analisar o comportamento do primeiro grupo tanto em termos de conteúdo (verificar se o tema está sendo discutido com precisão, objetividade e profundidade requerida) ou funcionamento (verificar se todos os participantes tem oportunidade para falar, se há existência ou não de regras de funcionamento interna, entre outros). A partir deste modelo inicial podem ocorrer variações do formato, da composição ou dos papéis exercidos pelos grupos, por exemplo. ${ }^{26}$

Por fim, uma das variações de ensino em grupo mais utilizadas no ensino superior é a técnica do "seminário", expressão que possui grande abertura semântica no ambiente escolar, sendo utilizado para designar diferentes propostas de ensino em pequenos grupos que, muitas vezes, são bem distantes dos objetivos tradicionais que orientam um seminário em termos técnicos. 0 seminário é um tipo especial de discussão que auxilia os estudantes no desenvolvimento de várias habilidades, tais como, o trabalho em equipe, a coleta de informações, a produção de conhecimento, a organização de idéias, na comunicação, na argumentação e na elaboração de relatório de pesquisa.

O seminário por sua própria etimologia (do latim "semem", semente) está relacionado as ideias de fertilização, vida nova, ideias novas. Em sentido amplo pode ser entendido como o trabalho elaborado por um grupo de pessoas que se reúnem para pesquisar e discutir um tema específico podendo ou não ser retratado por escrito e exposto para outros estudantes. Para Imídeo Nerici, o que caracteriza o seminário é justamente a pesquisa e discussão envolvendo assim atividades de ensino e pesquisa ${ }^{27}$.

A técnica pode ainda ser útil para o alcance de vários objetivos como na identificação de problemas; reformulação de problemas a partir de seu enfoque sob diferentes ângulos; proposição de pesquisas para solucionar problemas; formulação de hipóteses de pesquisa; acompanhamento de desenvolvimento de

${ }^{26}$ GIL, Antônio Carlos. Didática do ensino superior, p.171

27 NERICI, Imídeo G. Metodologia do ensino superior. Lisboa, Portugal: Fundo de Cultura, 1973 
OLIVEIRA; Cláudio Ladeira de; SILVA, Larissa Tenfen. Discussão e técnicas de ensino em grupo: ferramentas de aprendizagem no ensino do direito. Revista Eletrônica Direito e Política, Programa de Pós-Graduação Stricto Sensu em Ciência Jurídica da UNIVALI, Itajaí, v.10, n.4, $3^{\circ}$ quadrimestre de 2015. Disponível em: www.univali.br/direitoepolitica - ISSN 1980-7791.

pesquisas; comunicação de resultados obtidos em pesquisas; apreciação e avaliação de resultados de estudos e pesquisas.

Interessante ressaltar que existe um número grande de variações do sistema dos seminários sendo justamento por isso importante identificar suas características básicas. Uma delas é a necessidade de preparação prévia para a atividade. É importante uma preparação anterior dos alunos para a obtenção de um mínimo de conhecimento sobre o assunto que será tratado. Neste ponto o professor pode indicar textos-base e/ou linhas de pesquisa para orientar inicialmente 0 conhecimento dos alunos. Nesta etapa os alunos devem pesquisar sobre o tema tratado.

Outra característica é a existência do momento de discussão entre os alunos integrantes das equipes sobre o tema que será apresentado. Todavia é importante que a discussão também ocorra entre a equipe expositora e os demais membros ouvintes da classe.

A exposição é a fase do seminário na qual os membros das equipes repassam o conhecimento estudado para os demais ouvintes do seminário.

A apresentação de trabalhos escritos se constitui em importante etapa que pode variar desde a confecção de um simples resumo à elaboração de um texto pessoal sobre o assunto.

É importante destacar que o professor tem um papel extremamente importante para realização dos objetivos do seminário. A técnica de forma nenhuma é uma atividade que deve ser utilizada pelo professor como fuga de suas atividades normais em sala de aula. Seu papel é fundamental na orientação e coordenação de todas as fases do processo, ainda que muitas etapas estejam mais centradas nos alunos ${ }^{28}$.

Sobre os possíveis papéis desempenhados pelos discentes componentes dos grupos do seminário, pode-se ter um orientador que faz a indicação dos temas e bibliografia mínima a ser lida por todo o grupo; um relator que pode ficar com a função de aprofundamento de algum ponto; e um comentador geral. Tal como

28 GODOY, Arilda Schimidt; CUNHA, Maria Alexandra Viegas Cortez da. Ensino em pequenos grupos. In: MOREIRA, Daniel A. (Org). Didática do ensino superior: técnicas e tendências. São Paulo: Pioneira , 2003, p. 83-100 
OLIVEIRA; Cláudio Ladeira de; SILVA, Larissa Tenfen. Discussão e técnicas de ensino em grupo: ferramentas de aprendizagem no ensino do direito. Revista Eletrônica Direito e Política, Programa de Pós-Graduação Stricto Sensu em Ciência Jurídica da UNIVALI, Itajaí, v.10, n.4, $3^{\circ}$ quadrimestre de 2015. Disponível em: www.univali.br/direitoepolitica - ISSN 1980-7791.

ocorre na formação de outras variações de grupos de ensino, pode-se ter outros papéis a serem desenvolvidos pelos demais alunos da equipe. ${ }^{29}$

Interessante ressaltar que apesar do seminário trazer em si a "[...] idéia de que é função do terceiro grau preparar o aluno para a investigação científica, através da reflexão aprofundada de um determinado tema"30, tal característica nem sempre tem seu valor reconhecido pelos alunos diante da má aplicação realizada pelos professores.

Costuma-se chamar de seminário qualquer apresentação feita por estudantes em classe, até mesmo de resumos de capítulos de livros. Nessas apresentações, os alunos geralmente organizados em grupos, de forma semelhante a um jogral, fazem sua apresentação aos colegas e ao professor, que a tudo assiste sem interferir. Mas isso em nenhuma hipótese é seminário. É apenas uma aula expositiva que é dada pelos alunos.

O seminário, enquanto uma forma ampla de estudo, pode ser aplicado tanto em cursos de graduação como de pós-graduação, sendo, neste último caso, considerados como uma das principais estratégias didáticas adotadas. Todavia o professor não deve esquecer que quando adotar tal técnica na graduação a dinâmica deve ser um pouco diferente do uso na pós-graduação diante da diferença de maturidade e nível de conhecimento técnico e metodológico dos alunos. ${ }^{31}$ Os seminários em uma disciplina podem ser seminários sobre um tema já conhecido, visando ao aprofundamento e sistematização deste; seminários sobre temas não estudas, ainda pelos participantes do seminário; seminários sobre tema de pura investigação e para orientação de trabalhos de pesquisas pessoais, com a obrigação de apresentação de resultados ao grupo do seminário.

\footnotetext{
${ }^{29}$ Cf. NERICI, Imídeo G. Metodologia do ensino superior.
}

30 GODOY, Arilda Schimidt; CUNHA, Maria Alexandra Viegas Cortez da. Ensino em pequenos grupos. In: MOREIRA, Daniel A. (Org). Didática do ensino superior: técnicas e tendências, p. 88

31 É recomendável, por exemplo, que o seminário seja feito a partir de um texto-roteiro, de preferência produzido pelo próprio professor, distribuído com antecedência para os participantes; ou que o mesmo ofereça textos bases iniciais que servem como guias iniciais para compreensão do conteúdo; e que o professor tenha disponibilidade de atendimentos para dirimir eventuais dúvidas e realizar orientações sobre a pesquisa; bem como explicar a metodologia de pesquisa, caso haja necessidade e a dinâmica do modelo de seminário escolhido. Nerici faz uma distinção sobre a aplicação de modalidades de seminários para a graduação e a pós-graduação: o seminário se divide em pré-seminário e seminário propriamente dito. No pré-seminário, os estudantes são introduzidos na metodologia da pesquisa em geral e, principalmente, na metodologia de pesquisa da disciplina. Já no seminário, com os estudantes capacitados em metodologia científica, iniciam a pesquisa propriamente dita. Assim, o pré-seminário destinar-seia aos estudantes das primeiras séries universitárias enquanto o seminário para os alunos das séries finais (cf. NERICI, Imídeo G. Metodologia do ensino superior, p.166). 
OLIVEIRA; Cláudio Ladeira de; SILVA, Larissa Tenfen. Discussão e técnicas de ensino em grupo: ferramentas de aprendizagem no ensino do direito. Revista Eletrônica Direito e Política, Programa de Pós-Graduação Stricto Sensu em Ciência Jurídica da UNIVALI, Itajaí, v.10, n.4, $3^{\circ}$ quadrimestre de 2015. Disponível em: www.univali.br/direitoepolitica - ISSN 1980-7791.

Outra técnica muito utilizada e que proporciona a habilidade para a discussão mediante o ensino em grupo nos cursos de Direito é a técnica do "Júri Simulado", também denominado de "Júri Pedagógico". Esta atividade pode ser facilmente utilizada em sala de aula e normalmente produz um nível muito alto de motivação, integração e participação dos alunos, além de fomentar o debate e o senso crítico nos discentes. Conforme expõe o professor Geraldo Magela, "a técnica possibilita o treinamento de respostas a questões propostas, levando o grupo a uma atenção quanto à confirmação ou rejeição às respostas oferecidas." ${ }^{32}$ Além disso, a técnica pode ser útil para estimular a organização das reflexões sobre os problemas, a habilidade para responder questões. Enfim, tal técnica contribui para desenvolver a percepção do "endosso" e do "protesto" às questões apresentadas e estimula a capacidade de argumentação e a capacidade se síntese e ordenação do pensamento.

De forma muito simples, o júri simulado pode ser entendido como a simulação, por parte dos alunos, de um julgamento num tribunal, mediante 0 desenvolvimento de papéis definidos. A partir de um caso fictício ou real, exposto previamente pelo professor, os alunos participantes, após estudo, pesquisa e discussão entre os membros de suas equipes, buscam convencer a equipe dos jurados ou do juiz, da afirmação da sua tese (que tanto pode ser de acusação ou defesa) para resolução do caso em questão.

A técnica pode ser organizada de várias formas, devendo ter pelos menos a existência básica dos seguintes papéis previamente definidos: de um ou mais juízes; do representante ou da equipe de representante do Ministério Público, do Advogado de Defesa e dos Jurados. Os demais alunos poderão fazer parte do plenário. Cabe ao professor expor o caso com certa antecedência para que as equipes se prepararem, além fornecer todas as regras necessárias da função de cada papel a ser exercido, bem como das regras de uso do tempo e da palavra. Além disso, no momento da utilização da técnica, o professor deve orientar as equipes e intervir no caso de descontrole emocional entre os alunos. Uma variação possível do uso da técnica é a apresentada por Magela:

O professor distribui a turma em: Grupo A versus Grupo B [...] b. cada aluno deverá estar munido com o material de

\footnotetext{
$32 \quad$ MAGELA, $\quad$ Geraldo.
https://gmagela.wordpress.com/tecnicas-de-ensino/. Acesso em out. 2015.
}

Disponível em: 
OLIVEIRA; Cláudio Ladeira de; SILVA, Larissa Tenfen. Discussão e técnicas de ensino em grupo: ferramentas de aprendizagem no ensino do direito. Revista Eletrônica Direito e Política, Programa de Pós-Graduação Stricto Sensu em Ciência Jurídica da UNIVALI, Itajaí, v.10, n.4, $3^{\circ}$ quadrimestre de 2015. Disponível em: www.univali.br/direitoepolitica - ISSN 1980-7791.

estudo e bem informado sobre a atividade; c. o professor indica um exercício para ser resolvido e marca o tempo de resolução; d. terminado o tempo, o Juiz (geralmente o professor ou um bom aluno) indica um da equipe A para responder; e. assim que houver a resposta, o seu advogado (da equipe A), diz: endosso (isto é, concordo com a resposta); f. o advogado opositor (equipe B), se concordar com a resposta, diz: confirmo. Se não concordar, diz: protesto; g. se o endosso for certo, a equipe A ganha um ponto. Se o endosso for errado, o juiz propõe uma rebatida ao plenário, que terá a oportunidade de reconsiderar a questão. O primeiro que se manifestar e corrigir o erro, seja da A ou da B, ganha um ponto para si cinco (5) pontos, e para o grupo um ponto; h. se o advogado opositor protestar o erro endossado, ele deverá indicar um componente do seu grupo para responder. Se a resposta for certa, o grupo ganha um ponto e ganha a vez da saída para a próxima questão; i. se o advogado protestar o certo (ou o errado), dar-se-á o debate entre os advogados, e o que vencer, mostrando o certo, ganhará para si cinco pontos e cinco para o grupo; j. poderá haver continuidade do processo em duas ou mais reuniões, se o conteúdo o permitir; k. deverá haver rodízio de advogados, promotores e juiz; l. é aconselhável, caso haja avaliação, converter os pontos obtidos em notas de aproveitamento; m. no manejo da classe, no trabalho, o juiz deverá mencionar o evangelizando que deve responder, assim: Aluno 3, na mesa 2, responda. Se a resposta não for dada de imediato, o aluno não terá direito de recorrer ao seu advogado, perdendo um ponto e a vez. ${ }^{33}$

Diante das várias possibilidades demonstradas da utilização da discussão por meio do ensino em grupo fica evidente como tais ferramentas podem ser eficazes como recursos de fomente a aprendizagem, bem com a realização de um ensino com vistas à formação crítica, reflexiva, autônoma, participativa e inclusiva dos alunos na área do Direito. Tal tendência vem sendo enfatizada pelos principais analistas e estudiosos do ensino jurídico ${ }^{34}$, bem como pelo

\footnotetext{
33 MAGELA, Geraldo. Técnicas de ensino, s/p.

34 SOBRINHO, José Wilson Ferreira. Metodologia do ensino jurídico e avaliação em direito. Porto Alegre: Fabris, 1997; FILHO, Álvaro Melo. Metodologia do ensino jurídico. 2. ed. Rio de Janeiro:Forense, 1979; RODRIGUES, Horácio Wanderlei (Org.). Ensino jurídico para que(m)? Florianópolis: Fundação Boiteux, 2000; ARRUDA JR, Edmundo Lima de. Ensino jurídico e
} 
OLIVEIRA; Cláudio Ladeira de; SILVA, Larissa Tenfen. Discussão e técnicas de ensino em grupo: ferramentas de aprendizagem no ensino do direito. Revista Eletrônica Direito e Política, Programa de Pós-Graduação Stricto Sensu em Ciência Jurídica da UNIVALI, Itajaí, v.10, n.4, $3^{\circ}$ quadrimestre de 2015. Disponível em: www.univali.br/direitoepolitica - ISSN 1980-7791.

próprio Ministério da Educação que, através da Resolução n. 9 CNE/CES, estatuiu as novas Diretrizes Curriculares Nacionais dos Cursos de Direito:

Art. 30. O curso de graduação em Direito deverá assegurar, no perfil do graduando, sólida formação geral, humanística e axiológica, capacidade de análise, domínio de conceitos e da terminologia jurídica, adequada argumentação, interpretação e valorização dos fenômenos jurídicos e sociais, aliada a uma postura reflexiva e de visão crítica que fomente a capacidade e a aptidão para a aprendizagem autônoma e dinâmica, indispensável ao exercício da Ciência do Direito, da prestação da justiça e do desenvolvimento da cidadania.

Art. 40. O curso de graduação em Direito deverá possibilitar a formação profissional que revele, pelo menos, as seguintes habilidades e competências: I - leitura, compreensão e elaboração de textos, atos e documentos jurídicos ou normativos, com a devida utilização das normas técnicojurídicas; II - interpretação e aplicação do Direito; III pesquisa e utilização da legislação, da jurisprudência, da doutrina e de outras fontes do Direito; IV - adequada atuação técnico-jurídica, em diferentes instâncias, administrativas ou judiciais, com a devida utilização de processos, atos e procedimentos; V - correta utilização da terminologia jurídica ou da Ciência do Direito; VI - utilização de raciocínio jurídico, de argumentação, de persuasão e de reflexão crítica; VII - julgamento e tomada de decisões; e, VIII - domínio de tecnologias e métodos para permanente compreensão e aplicação do Direito.

\section{CONSIDERAÇÕES FINAIS}

O ensino do Direito passa por um momento de debate e reformulação das atividades docentes, em especial, aquelas desenvolvidas em sala de aula, em face na necessidade de fomentar metodologias que a um só tempo desenvolvam as necessárias habilidades e competências aos novos bacharéis em Direito, como tornem as aulas mais estimulantes e reflexivas, tanto para os professores, como para os alunos.

sociedade: formação, trabalho e ação social. São Paulo: Acadêmica, 1980; MARTINEZ, Sérgio Rodrigo. A evolução do ensino jurídico no Brasil. Disponível em:<www.ensinojuridico.pro.br>. Acesso em: 20 jan. 2012. 
OLIVEIRA; Cláudio Ladeira de; SILVA, Larissa Tenfen. Discussão e técnicas de ensino em grupo: ferramentas de aprendizagem no ensino do direito. Revista Eletrônica Direito e Política, Programa de Pós-Graduação Stricto Sensu em Ciência Jurídica da UNIVALI, Itajaí, v.10, n.4, $3^{\circ}$ quadrimestre de 2015. Disponível em: www.univali.br/direitoepolitica - ISSN 1980-7791.

Neste sentido, acredita-se que a discussão e as técnicas de ensino em grupo são recursos didáticos que quando combinados apresentam grandes possibilidades de contribuição na relação de ensino-aprendizagem, podendo ser facilmente aplicadas em contextos de sala de aula.

A discussão é uma técnica que busca desenvolver ou aprimorar nos alunos uma série de habilidades, competências e características que contribuem para a formação técnica dos futuros profissionais, bem como para o próprio desenvolvimento pessoal dos alunos. Nesse sentido, a forma escolhida de como trabalhar com a discussão mediante 0 formato em grupo ajuda a instrumentalizar e oportunizar a realização destes pressupostos.

Uma das principais finalidades do ensino superior é de capacitar tecnicamente os estudantes para o exercício profissional em certa área do conhecimento, mas também de contribuir na formação pessoal e cidadã dos indivíduos atuantes e participantes de certa sociedade. Esta dimensão mais particularizada é importante para contribuição do aprimoramento da personalidade dos alunos que logo passam a ser vistos como profissionais que objetivam a realização pessoal que perpassa pela ascensão social, financeira, intelectual, ou seja, alguns pressupostos para melhor transitar e viver nas sociedades atuais. E é justamente destes indivíduos que se espera uma maior compreensão dos contextos em que vivem, das relações políticas, sociais econômicas, internacionais que existem na sociedade, e que passem a agir de forma a contribuir minimamente para a concretização de um país melhor, ou seja, dos fundamentos e objetivos da República Federativa, tal como estabelecido na Constituição Federal de 1988. Afinal, a educação formal está justamente a serviço dos indivíduos e da sociedade.

Entretanto, o professor não pode esquecer que a escolha de determinada estratégia deve resultar dos objetivos e necessidades específicas, já que existem situações ou contextos que é mais apropriado a escolha de outros recursos existentes, ficando patente que esse não é um método de ensino que possa ser utilizado para ensinar tudo a todos. Atento a isto, o professor tem a seu alcance um instrumental muito eficaz para contribuir para uma relação de ensino e aprendizagem permeados pelos preceitos de um ensino dinâmico, socializante, reflexivo, crítico, instigante, inclusivo e participativo. 
OLIVEIRA; Cláudio Ladeira de; SILVA, Larissa Tenfen. Discussão e técnicas de ensino em grupo: ferramentas de aprendizagem no ensino do direito. Revista Eletrônica Direito e Política, Programa de Pós-Graduação Stricto Sensu em Ciência Jurídica da UNIVALI, Itajaí, v.10, n.4, $3^{\circ}$ quadrimestre de 2015. Disponível em: www.univali.br/direitoepolitica - ISSN 1980-7791.

\section{REFERÊNCIAS DAS FONTES CITADAS}

ALCANTARA, Alcides. A dinâmica de grupos e sua importância no ensino. Rio de Janeiro: Senai, 1973.

ALMEIDA, Paulo Nunes. 0 ensino globalizante em dinâmica de grupo. São Paulo: Saraiva, 1973.

ARRUDA JR, Edmundo Lima de. Ensino jurídico e sociedade: formação, trabalho e ação social. São Paulo: Acadêmica, 1980.

FREIRE, Paulo. Pedagogia da autonomia: saberes necessários à prática educativa. São Paulo: Paz e Terra, 2011.

FILHO, Álvaro Melo. Metodologia do ensino jurídico. 2. ed. Rio de Janeiro: Forense, 1979.

GIL, Antônio Carlos. Metodologia do ensino superior. 3. ed. São Paulo: Atlas, 1997.

Didática do ensino superior. São Paulo: Atlas, 2006.

GODOY, Arilda Schimidt; CUNHA, Maria Alexandra Viegas Cortez da. Ensino em pequenos grupos. In: MOREIRA, Daniel A. (Org). Didática do ensino superior: técnicas e tendências. São Paulo: Pioneira, 2003, p. 83-100.

MAGELA, Geraldo. Técnicas de ensino. Disponível em: https://gmagela.wordpress.com/tecnicas-de-ensino/. Acesso em out. 2015.

LIBANEO, José Carlos. Didática. São Paulo: Cortez, 1994.

LOWMAN, Joseph. Dominando as técnicas de ensino. Trad. Harue Ohara Avritscher. São Paulo: Atlas, 2004.

MARTINEZ, Sérgio Rodrigo. A evolução do ensino jurídico no Brasil. Disponível em: <www.ensinojuridico.pro.br>. Acesso em: 20 jan. 2012.

BRASIL (Ministério da Educação). Resolução n. 9 CNE/CES. Brasília, DF, 2004. GODOY, Arilda Schimidt; CUNHA, Maria Alexandra Viegas Cortez da. Ensino em pequenos grupos. In: MOREIRA, Daniel A. (Org). Didática do ensino superior: técnicas e tendências. São Paulo: Pioneira , 2003, p. 173.

MUCCHIELLI, R. A formação de adultos. São Paulo: Martins Fontes, 1981

NERICI, Imídeo G. Metodologia do ensino superior. Lisboa, Portugal: Fundo de Cultura, 1973.

RODRIGUES, Horácio Wanderlei (Org.). Ensino jurídico para que(m)? Florianópolis: Fundação Boiteux, 2000.

SOBRINHO, José Wilson Ferreira. Metodologia do ensino jurídico e avaliação em direito. Porto Alegre: Fabris, 1997.

TURRA, Clódia Maria Godoy et al. Planejamento de ensino e avaliação. 11. ed. Porto Alegre: Sagra Luzzatto, ano 1975.

VENTURA, Deisy. Ensinar direito. Barueri, SP: Manole, 2004.

VILARINHO, Lúcia Regina Goulart. Didática: temas selecionados. Rio de Janeiro: LTC, 1979.

\section{Legislação}

BRASIL. Ministério da Educação. Portaria no $\mathbf{1 . 8 8 6 / 9 4}$. Disponível em http://portal.mec.gov.br/sesu/arquivos/pdf/dir_dire.pdf. Acesso em 09/07/2015

BRASIL. Conselho Nacional de Educação. Parecer no 67/2002, publicado no Diário Oficial da União de 2/6/2003. Referencial para as Diretrizes Curriculares Nacionais - DCN dos Cursos de Graduação. Disponível em http://portal.mec.gov.br/cne/arquivos/pdf/2003/pces067_03.pdf. Acesso em 09/07/2015 
OLIVEIRA; Cláudio Ladeira de; SILVA, Larissa Tenfen. Discussão e técnicas de ensino em grupo: ferramentas de aprendizagem no ensino do direito. Revista Eletrônica Direito e Política, Programa de Pós-Graduação Stricto Sensu em Ciência Jurídica da UNIVALI, Itajaí, v.10, n.4, $3^{\circ}$ quadrimestre de 2015. Disponível em: www.univali.br/direitoepolitica - ISSN 1980-7791.

BRASIL. Ministério da Educação. Conselho Nacional da Educação. Resolução no 9, de 29 de setembro de 2004. Institui as Diretrizes Curriculares Nacionais do curso de graduação em Direito, bacharelado, e dá outras providências. Disponível em http://portal.mec.gov.br/cne/arquivos/pdf/rces09_04.pdf. Acesso em 09/07/2015

Submetido em: Novembro/2015

Aprovado em: Dezembro/2015 